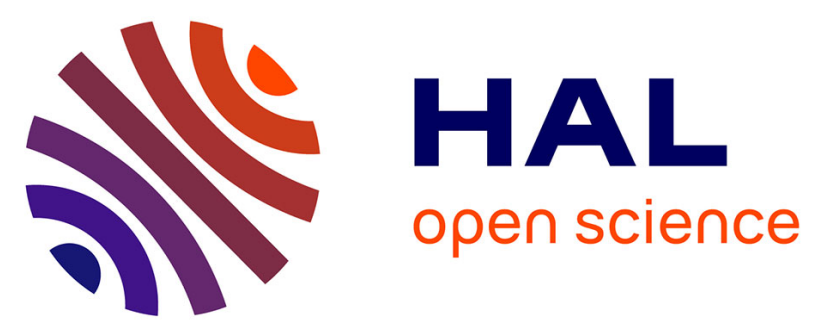

\title{
Sudden Decrease of the Dissolved Ozone Concentration in Sprays: A Mass Transfer Phenomenon?
}

\author{
Axel Canado, Marine Tournois, Marielle Pages, Michel Roustan, Wilfried \\ Remus-Borel, Nicolas Dietrich, Frédéric Violleau, Gilles Hébrard
}

\section{- To cite this version:}

Axel Canado, Marine Tournois, Marielle Pages, Michel Roustan, Wilfried Remus-Borel, et al.. Sudden Decrease of the Dissolved Ozone Concentration in Sprays: A Mass Transfer Phenomenon?. Industrial and engineering chemistry research, 2020, 59 (33), pp.14914-14924. 10.1021/acs.iecr.0c03216 . hal02936577

\section{HAL Id: hal-02936577 \\ https://hal.inrae.fr/hal-02936577}

Submitted on 23 Jun 2021

HAL is a multi-disciplinary open access archive for the deposit and dissemination of scientific research documents, whether they are published or not. The documents may come from teaching and research institutions in France or abroad, or from public or private research centers.
L'archive ouverte pluridisciplinaire HAL, est destinée au dépôt et à la diffusion de documents scientifiques de niveau recherche, publiés ou non, émanant des établissements d'enseignement et de recherche français ou étrangers, des laboratoires publics ou privés. 


\title{
The sudden decrease of the dissolved ozone concentration in sprays: a mass
}

\section{transfer phenomenon?}

$\underline{\text { Axel CANADO }}^{1}$, Marine TOURNOIS ${ }^{2}$, Marielle PAGES ${ }^{3,4}$, Michel ROUSTAN ${ }^{2}$, Wilfried REMUS-

\author{
BOREL ${ }^{5}$, Nicolas DIETRICH ${ }^{2}$, Frédéric VIOLLEAU ${ }^{1,4}$, Gilles HEBRARD ${ }^{2, *}$ \\ 1. Laboratoire de Chimie Agro-industrielle LCA, Université de Toulouse, INRAE, INP-PURPAN \\ Toulouse, France \\ 2. Toulouse Biotechnology Institute TBI, CNRS, INRAE, INSA, Université de Toulouse, France \\ ${ }^{3}$. Physiologie, Pathologie et Génétique Végétales (PPGV), Université de Toulouse, INP-PURPAN, \\ Toulouse, France \\ ${ }^{4}$. Plateforme TOAsT, Université de Toulouse, INP-PURPAN, Toulouse, France \\ 5. Belchim Crop Protection France, Parc Tertiaire de Bois Dieu, 3 allée des Chevreuils, Lissieu, \\ France \\ *. Corresponding author: Toulouse Biotechnology Institute,135 avenue de Rangueil 31077 Cedex \\ 4,Toulouse, France. Mail: gilles.hebrard@insa-toulouse.fr
}

\begin{abstract}
Ozone is known to be a powerful oxidant with low persistence and has been shown to possess biocidal activity against a wide number of fungi and bacteria. These properties make ozone a good candidate as a substitute for chemical phytosanitary products in agriculture. However, when water containing dissolved ozone is sprayed, the concentration of ozone decreases dramatically with the spraying distance. This study aims to better understand this ozone loss during spraying and, in particular to identify whether mass transfer occurs. Identification was performed by dioxygen absorption and comparison of its concentration profiles with those for ozone desorption. Droplets were collected at different heights in the spray to measure the dissolved concentrations. Image analysis was used to determine the diameters and velocities of the droplets. Ozone selfdecomposition kinetics were not able to explain the experimental concentration variation obtained in the droplets. The decrease of dissolved ozone in the liquid is then only caused by mass transfer. Most of the mass transfer seems to take place in the liquid sheet that leaves the nozzle. Volumetric
\end{abstract}


mass transfer coefficients have been assessed for different regions of the spray. From mass transfer correlations, a model has been made to predict the concentration profile in droplets of the spray.

\section{List of symbols}

$A \quad$ Area of a particle in the image $\left(\right.$ pixel $\left.^{2}\right)$

$a_{\text {droplets }}$ Interfacial area of the droplets $\left(\mathrm{m}^{2} / \mathrm{m}^{3}\right.$ liquid)

$a_{\text {droplets }}^{0}$ Interfacial area of the droplets $\left(\mathrm{m}^{2} \cdot \mathrm{m}^{-3}\right.$ reactor $)$

$a_{\text {film }}$ Interfacial area of the film $\left(\mathrm{m}^{2} / \mathrm{m}^{3}\right.$ liquid)

$a_{\text {film }}^{0} \quad$ Interfacial area of the film $\left(\mathrm{m}^{2} \cdot \mathrm{m}^{-3}\right.$ reactor $)$

C Concentration $\left(\mathrm{mg} \cdot \mathrm{L}^{-1}\right)$

d Droplet diameter (m)

$d_{e q} \quad$ Equivalent diameter (m)

$d_{32} \quad$ Sauter diameter $(\mathrm{m})$

$D_{A B} \quad$ Diffusion coefficient of $\mathrm{A}$ in $\mathrm{B}\left(\mathrm{m}^{2} \cdot \mathrm{s}^{-1}\right)$

$D \quad$ Distance travelled between 2 images (m)

$H \quad$ Height in the contactor (m)

$k_{D} \quad$ Ozone self-decomposition reaction constant

$k_{L} \quad$ Liquid side mass transfer coefficient $(\mathrm{m} / \mathrm{s})$

$k_{L} a \quad$ Volumetric mass transfer coefficient $\left(\mathrm{m}^{-1}\right)$

$L \quad$ Length of the liquid film (m)

$l \quad$ Width of the liquid film (m)

$N_{\text {droplets }}$ Number of droplets in the contactor

$Q_{L} \quad$ Liquid flow rate $\left(\mathrm{m}^{3} \cdot \mathrm{s}^{-1}\right)$

Re Reynolds number $=\rho_{L} \cdot U \cdot d / \mu_{L}$

$r_{O_{3}} \quad$ Ozone self-decomposition reaction rate $\left(\mathrm{s}^{-1}\right)$

$S \quad$ Surface $\left(\mathrm{m}^{2}\right)$

$S_{1 \text { droplet }}$ Surface area of one droplet $\left(\mathrm{m}^{2}\right)$

Sc Schmidt number $=\mu_{L} /\left(\rho_{L} \cdot D_{A B}\right)$

Sh Sherwood number

$t \quad$ Time (s)
$U \quad$ Velocity of the droplet $(\mathrm{m} / \mathrm{s})$

V Volume $\left(\mathrm{m}^{3}\right)$

$V_{1 \text { droplet }}$ Volume of one droplet $\left(\mathrm{m}^{3}\right)$

$\Delta C_{\text {exp }} \quad$ Concentration variation measured $(\mathrm{mg} / \mathrm{L})$

$\Delta C_{\max }$ Maximum concentration variation reachable $(\mathrm{mg} / \mathrm{L})$

\section{Greek symbols}

$\alpha \quad$ Solubility ratio (-)

$\rho \quad$ Volumetric mass density $\left(\mathrm{kg} / \mathrm{m}^{3}\right)$

(2) Viscosity (Pa.s)

$\Omega \quad$ Section of the contactor $\left(\mathrm{m}^{2}\right)$

$\tau \quad$ Residence time of the liquid in the contactor

(s)

$\delta \quad$ Thickness of the liquid film (m)

\section{Subscripts}

$0 \quad$ relative to the initial concentration

$k \quad$ relative to the $\mathrm{k}$-th particle

$j \quad$ relative to a given solute $\left(\mathrm{O}_{3}\right.$ or $\left.\mathrm{O}_{2}\right)$

$\mathrm{O}_{2} \quad$ relative to oxygen molecule

$\mathrm{O}_{3} \quad$ relative to ozone

$H \quad$ relative to the concentration at the height $\mathrm{H}$

$A D X \quad$ relative to the ADX nozzle

$A F X \quad$ relative to the AFX nozzle

droplet relative to the droplet region

Film relative to the film region

\section{Superscripts}

$L \quad$ relative to the liquid phase

G relative to the gas phase 
relative to the saturation state

Introduction

3 Numerous processes require an effective oxidizing action to treat organic, mineral and biological

4 substances. Processes such as water disinfection, decolourization of dyes, abatement of carbon

5 organic demand and elimination of volatile organic compounds use ozone $\left(\mathrm{O}_{3}\right)$ as the oxidizing

6 agent[1-3]. Ozone is very suitable for all these operations since its oxidative power is considerably

7 higher than those of chlorine or hydrogen peroxide, for example. As a result, it is highly reactive

8 with a wide range of species. Applications using ozone rely on direct action of the $\mathrm{O}_{3}$ molecule on

9 a carbon double bond. There are also indirect actions based on the reactivity of Reactive Oxygen

10 Species (ROS), such as $\mathrm{H}_{2} \mathrm{O}_{2},{ }^{\circ} \mathrm{OH},{ }^{-} \mathrm{O}_{2}$ formed by the reaction of $\mathrm{O}_{3}$ with water constituents [4].

11 Due to its reactivity, ozone has a lifetime of about 20 minutes at $20^{\circ} \mathrm{C}$ in water and most of its

12 reaction pathways lead to dioxygen formation [5]. This behaviour can be an inconvenient in

13 wastewater treatment, where the persistence of the molecule in the tap water is important to

14 ensure good disinfection throughout the treatment unit. Furthermore, ROS are involved in

15 numerous complex mechanisms and are arousing growing interest in the literature as their

16 oxidative potentials are higher than that of ozone [6-9].

18 Several studies have highlighted the properties of ozone and its by-products for damaging 19 microorganisms in vitro [10,11]. This action of ozone has inspired studies in the field of agri-food, 20 for the protection of plants and crops or for surface disinfection [12,13]. Combating crop diseases 21 is one of the main concerns for growers, especially since some phytosanitary products are controversial because of their impacts on the environment and human health [14]. The challenge in

23 this field of research is to prove that ozone could be integrated into conventional programmes to 24 reduce the doses of chemical products required for plant protection. For this kind of application, the 25 strong oxidizing power and low persistence of the ozone molecule, which decomposes into 26 dioxygen in water would be an advantage to avoid environment contamination [1,5]. With this 27 challenge in mind, several authors have compared treatment by ozone with conventional 
treatment, obtaining encouraging results $[15,16]$. Most of the experiments have been performed in controlled conditions to assess the effect of the two treatments and in situ applications are rarely reported in the literature. In agriculture, in situ experiments require the treatment of a considerable surface area due to the number of leaves present on plants and trees. Thus, the main way of applying a treatment is spraying as it enables a large surface area to be treated using a small amount of liquid.

However, applying ozonated water (OW) seems to be difficult. Some studies have experimented the spraying of ozonated water for agri-food concerns. Using pears and shrimps, respectively, Spotts et al. [17] and Chawla et al. [18] compared immersion and spraying techniques for the application of OW. They showed that the spraying was ineffective while immersion gave a greater bacterial reduction. When spraying with a distance of $2 \mathrm{~cm}$ between the nozzle and the target, Ebihara et al. [19] obtained considerable insect sterilization but noticed a rapid decrease of efficiency when the distance of pulverization was increased. The well-known efficiency of ozone on microorganisms in vitro was not reached for these experiments of ozone application by spraying.

Fujiwara et al. [20] investigated the spraying of ozonated water and showed that the concentration of dissolved ozone in droplets decreased drastically over the distance of pulverization, especially in the first few centimetres after the nozzle. For these authors, this loss could be explained by autolysis of ozone to dioxygen, caused by the turbulence occurring with the crossing of the nozzle. Tournois et al. showed [21] that the same concentration decrease was observed when trying to pulverize ozonated water. To explain this concentration drop, they proposed a diffusion of ozone molecules from the liquid droplets to the air during the droplets' journey in the spray. This behaviour of the solute is commonly described by mass transfer theories, based on diffusion phenomena coupled with hydrodynamics principles [22]. Although most of the community agreed on the diffusion phenomenon as the reason for this concentration drop, studies identifying ozone mass transfer in sprays are rarely, if ever, present in the literature. Moreover, even though 
scientific studies have noted the loss of dissolved ozone in droplets, some companies are commercializing devices for spraying ozonated water, in spite of their efficiency being contested.

4 The transfer of a solute from one phase to another can be characterized using an overall

5 measurement of the system. This means that the concentration of the solute in a phase is 6 measured at the inlet and the outlet of the system to assess the quantity of solute leaving the 7 phase of interest. Such measurements allow the efficiency of gas-liquid contactors' to be compared 8 but do not describe any mechanisms in the system [23]. The problem of such a characterization is

9 that the solute loss observed could be caused by reaction of the solute with dissolved compounds.

10 Knowledge of the transfer rate or the reaction rate would allow us to assess the extent of which 11 each phenomenon is involved in the solute loss.

The main goal of the present study was to provide a better understanding of the loss of dissolved ozone in droplets during spraying. Solute quantifications along the spray allowed a distinction to be made between an ozone mass transfer phenomenon and its self-decomposition. Thus, overall 16 characterizations were performed at different distances from the atomizer to track the 17 concentration of solute dissolved in the spray. From the measurements, the volumetric mass 18 transfer coefficient $k_{L} a$ was assessed for different regions of the spray (Film region and droplets 19 region) to highlight the part of the spray where transfer was the most noteworthy. From image 20 analysis, the interfacial area of each region has been assessed, then the corresponding $k_{L}$ has 21 also been estimated. A model able to describe the concentration profile of dissolved ozone along 22 the spraying distance has been built. This paper may also provide a way to encourage sellers of 23 OW sprayers to exercise caution when claiming to reproduce the in vitro effect of OW with spraying 24 techniques 
Materials and methods

\section{$3 \quad$ I-Mass transfer identification and overall characterization}

4

1) Experimental set-up

6 The goal of this experimental set-up was to prove that the loss of ozone observed during the

7 spraying of ozonated water was due only to mass transfer as Tournois et al. [21] suggested. On

8 the one hand, the mass transfer of $\mathrm{O}_{3}$ was studied in a desorption case and, on the other hand, the

9 absorption of $\mathrm{O}_{2}$ in water was studied.

10 The experimental set-up consisted of a spraying nozzle that atomized liquid from a tank by means

11 of a pump. Atomization was performed using fan spray nozzles from Nozal: ADX-120-02 (a nozzle 12 with air suction) and a fan spray nozzle without air suction (AFX-80-02). The ADX nozzle produces 13 a spray with an angle of $120^{\circ}$ whereas the AFX makes an $80^{\circ}$ spray angle. Both nozzles were 14 used with a flowrate $Q_{L}$ of $45 \mathrm{~L} / \mathrm{h}$. A sintered connected to 2 different gas feeds are immersed into 15 the thank to ensure a constant concentration of gas solute into the liquid storage. Fig. 1 represents 16 the set-up:
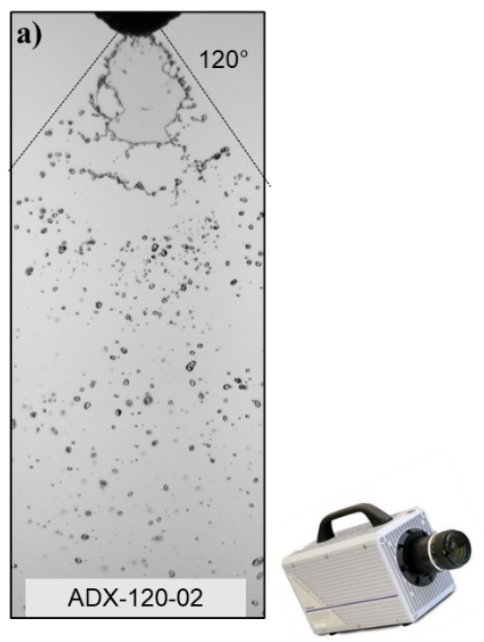

High Speed Camera b)

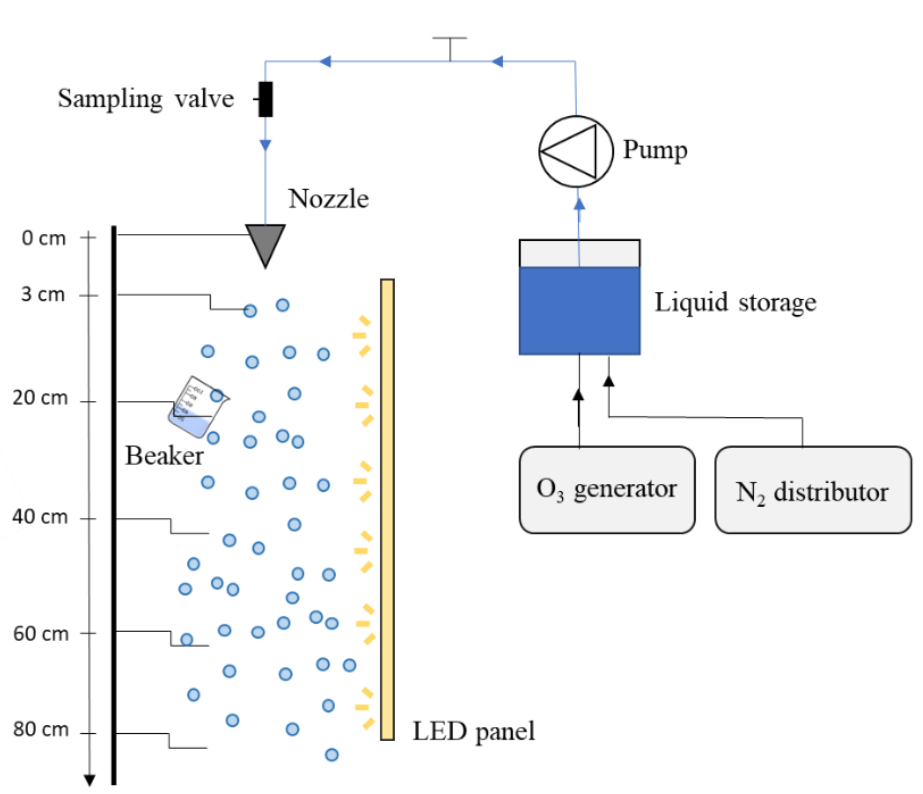


Fig.1. Experimental set-up for concentration and hydrodynamics measurements (b) and the 2 fan nozzles used (a-c)

3 Depending on the gas feed that is bubbled through the sintered, two distinct mass transfer conditions can be managed.

5 Ozone desorption:

6 Desorption condition is set by bubbling ozone in distilled water contained in the liquid storage. 7 Ozone gas is produced by corona discharge in a pure dioxygen stream. The bubbling is performed 8 until saturation concentration of dissolved ozone is reached into the tank. This step ensures the total consumption of any instantaneous ozone demand from the water. Ozone concentration in the

10 air is negligible, then the corresponding dissolved saturation concentration is neglected $\left(\alpha C_{O_{3}}^{G}=\right.$ $11 \cos *, L=0$ ). The bubbling of ozone in the liquid increase the actual dissolved concentration, then 12 the driving force $\left(C_{O_{3}}^{*, L}-C_{O_{3}}^{L}\right)$ is expected to be negative. This indicates that ozone will diffuse from 13 the liquid phase to the gas phase, it is a desorption condition.

\section{Oxygen Absorption:}

15 To promote absorption condition, the dissolved concentration of solute in the liquid needs to be 16 lower than the saturation concentration. Nitrogen gas is bubbled in the liquid storage to decrease 17 the dioxygen concentration in the liquid until it can be neglected $\left(C_{O_{3}}^{L} \approx 0\right)$. Air being composed of $21 \%$ of $\mathrm{O}_{2}$, the saturation concentration of dissolved of dioxygen is expected to be higher than the 19 actual dissolved concentration reached by nitrogen bubbling. Then the driving force $\left(C_{O_{2}}^{*, L}-\right.$ 20 CO2L will be positive, meaning that dioxygen will diffuse from the gas phase to the liquid phase.

21 This is the absorption condition.

A high-speed camera and a LED panel are placed on both sides of the spray to take pictures of the droplets stream. Spraying was performed few seconds after the bubbling was stopped to avoid any bubble in the tubing that would disturb the flow of the spray. A holder maintained the nozzle and allowed to bear a beaker at different height in the liquid stream to collect droplets. 
2) Concentration measurements:

2 To track the mass transfer occurring in the spray, concentration measurements are made at

3 different height in the spray $(0.03 m-0.2 m-0.4 m-0.6 m$ and $0.8 m)$. For each height, liquid is

4 collected in a beaker, and the collected sample is analysed depending on the solute.

\section{Ozone desorption:}

6 For the ozone desorption, measurements of dissolved ozone were performed by the indigo method [24]. Indigo is a blue dye and the ozone molecule reacts with the single carbon double bond present in the indigo molecule to form a colourless compound. Thus, measuring the discolouration of the solution by absorbance led to the quantification of dissolved ozone. Droplets were collected in a basic $25 \mathrm{~mL}$ beaker at different heights from the nozzle. The beaker is $50 \mathrm{~mm}$ height with a 11 diameter of $34 \mathrm{~mm}$. For each fresh sample, $5 \mathrm{~mL}$ of the liquid collected was immediately added to 5 $\mathrm{mL}$ of the indigo solution. It took no more than $5 \mathrm{~s}$ to collect enough droplet and to sample them. The concentration of the sample was determined by absorbance measurement at $\lambda=600 \mathrm{~nm}$ with upstream the nozzle.

\section{Oxygen Absorption:}

18 For oxygen absorption, an oxygen optical probe $\left(\mathrm{HACH}\right.$ - Intellical ${ }^{\mathrm{TM}}$ LDO101 Laboratory

a Spectronic Helios Gamma UV-Vis spectrophotometer (Thermo Fisher Scientific). The initial concentration was determined by applying the indigo method from a sample taken in the tubing Luminescent/Optical Dissolved Oxygen Sensor) was used to determine the concentrations of dioxygen dissolved in droplets, with an accuracy of $\pm 0.1 \mathrm{mg} / \mathrm{L}$ from 0.1 to $8 \mathrm{mg} / \mathrm{L}$. The initial concentration was found by immersing the probe in the feeding tank, and intermediate concentrations were measured by immersing the probe in the beaker, once the beaker was full enough. The beaker was tilted slightly to ensure constant renewal of the liquid collected.

For both cases, the concentration measured in the bulk liquid in the beaker was considered as the concentration inside the droplets at the height of collection. The swirls and eddies produced by the impact of droplets on the bulk liquid surface created convection motions. Thus, the turbulence in 
the bulk liquid could enhance the mass transfer, especially when the collection occurred close to the nozzle ( $3 \mathrm{~cm}$ away). As these convections motions when collecting droplets occurred for each measurement, this bias is repeated for each measurement, then the evolution measured should

4 remain consistent.

5 Spraying being performed in ambient air, gas phase confinement for concentration measurement 6 was not convenient. Then, only dissolved concentrations are determined in the present study.

3) Ozone decomposition estimation

9 The decrease of ozone in the liquid phase can be due to a transfer phenomenon and/or a reaction

10 of decomposition of the $\mathrm{O}_{3}$ molecule in $\mathrm{O}_{2}$. To determine the extent of the variation of ozone due to 11 reaction, an estimation of the reaction rate is done. The rate of self-decomposition of ozone depends on several parameters such as $\mathrm{pH}$ of the solvent, ionic strength, temperature, or agitation.

13 A kinetic constant $\left(k_{D}=0.001 \mathrm{~s}^{-1}\right)$ in first order respect to ozone has been used for distilled water at $1420^{\circ} \mathrm{C}$ and $\mathrm{pH}=7$ [32]:

$$
\frac{d C_{O_{3}}^{L}}{d t}=r_{O_{3}}=k_{D} C_{O_{3}}^{L}
$$

16 The dissolved concentration of ozone has been considered constant and equal to its initial value. 17 The duration of the reaction is determined as the residence time of the liquid from the nozzle to the 18 point of collection.

4) Hydrodynamic of the spray

a. Droplets diameters and velocities. Mass transfer characterization relies on the hydrodynamic determination of the gas-liquid system. In the case of a spray, diameters and velocities of the droplets produced are the main parameters

24 to assess. Hydrodynamic determination is performed by image analysis.

25 A high-speed camera (APX Photron), equipped with a $60 \mathrm{~mm}$ lens (AF Micro-Nikkor - Nikon) took 26 images of the spray at 2000 frames per second. Shutter speed was $1 / 75000$ second to allow the 
acquisition of particles with considerable velocities. With this fast shutter speed, a large amount of

2 light was needed, so an LED panel (LitePad HO LED - Rosco) was set behind the spray. The

3 camera was connected to a computer so that images could be recorded using the Photron

4 FASTCAM Viewer software.

5 Diameters were determined by evaluating the area $A$ (in pixels ${ }^{2}$ ) of each particle on 300 images. $^{2}$

6 The area of the droplet was obtained through common image analysis procedure [25]. From this

7 area, equivalent diameters were calculated, assuming that particles were spherical:

$$
d_{e q}=\sqrt{\frac{4 A}{\pi}}
$$

9 Once an equivalent diameter had been associated with each droplet of the spray, an average 10 diameter for the spray was determined using the Sauter diameter definition [26]. The Sauter 11 diameter has been used as a unique value to characterize the whole spray $\left(d=d_{32}\right)$.

$$
d_{32}=\frac{\sum_{0}^{k} n_{k} d_{e q, k}^{3}}{\sum_{0}^{k} n_{k} d_{e q, k}^{2}}
$$

Velocities measurements relies on the identification of the displacement of a particle between two pictures. In the present study, the time spent between two pictures was too high to apply a displacement correlation algorithm on the pictures. Then we decided to make this identification with

18 the naked eye. That was a time-consuming method. On 20 pictures, only 3 droplets have been recognized between 2 pictures. Those droplets were not chosen because of their representativeness of the spray, but because their displacement between 2 pictures were identifiable. Then, 3 particles are not statistically sufficient to represent the spray, but it gives a good estimation of the velocity in the spray.

23 The velocity was calculated by extracting the droplet coordinates with the GIMP software for each 24 image, the distance travelled and the time $\Delta t(1 / 2000 \mathrm{~s})$ between 2 images being known: 


$$
U=\frac{D}{\Delta t}=\frac{\sqrt{\left(x_{2}-x_{1}\right)^{2}+\left(y_{2}-y_{1}\right)^{2}}}{\Delta t}
$$

3 The velocities obtained were averaged to characterize the whole spray. An example of coordinate

4 determination is shown in Fig. 2.

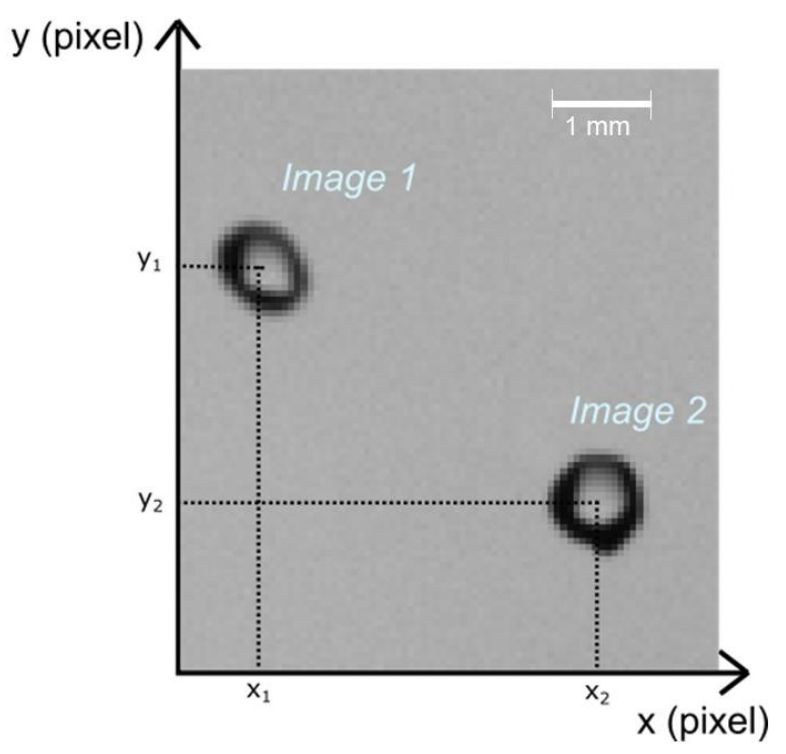

5

6 Fig.2. An example of coordinates determination with two images superimposed using the GIMP software

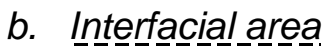

8 Determining the interfacial area offered by the liquid for the mass transfer is necessary. For the

9 droplets, the interfacial area is defined as:

$$
a_{\text {droplets }}=\frac{S_{L}}{V_{L}}=\frac{N_{\text {droplets }} S_{1 \text { droplet }}}{V_{L}}=\frac{\frac{V_{L}}{V_{1 \text { droplet }}} S_{1 \text { droplet }}}{V_{L}}=\frac{6}{d}
$$

11 The area offered by volume of contactor can also be defined for the droplets, considering a 12 cylindrical section $\Omega$ of $20 \mathrm{~cm}$ diameter:

$$
a_{\text {droplets }}^{0}=\frac{S_{L}}{H \Omega}=\frac{\frac{6}{d} Q_{L} \tau}{H \Omega}
$$


1 Before droplets are atomized, a flat liquid sheet is present at the exit of the nozzle. It is

2 characterized as a rectangular prism with a length $L$, a width $l$ and a thickness $\delta$. Pictures have

3 been taken from the front and the side view of this liquid film to estimate those parameters. For this

4 liquid film, the interfacial area is defined as:

$$
a_{f i l m}=\frac{S_{L}}{V_{L}}=\frac{2 L l+4(L \delta)}{\delta L l}
$$

5

6 It can also be expressed regarding the volume of contactor:

$$
a_{f i l m}^{0}=\frac{S_{L}}{H \Omega}=\frac{2 L l+4(L \delta)}{H \Omega}
$$

\section{5) Mass transfer model}

a. Mass_balances.

11 A model was constructed to determine the concentration of a solute in the droplets along the spraying distance. The variation in concentration inside a droplet by mass transfer over time is commonly express this way:

$$
\frac{d C_{j}}{d t}=k_{L} a\left(C_{j}^{L, *}-C_{j}^{L}\right)
$$

15 Reorganizing Eq (9) leads to:

$$
\frac{d C_{j}}{\left(C_{j}^{L, *}-C_{j}^{L}\right)}=k_{L} a d t
$$

17 Integration of the concentration over time for the spherical element of fluid considered leads to the

18 following expression. The time is integrated from the moment where the liquid leaves the nozzle to

19 the moment where droplets are collected. This time of contact between the gas phase and the 20 liquid is assumed to be the distance travelled in the gas phase $(H)$ divided by the droplet's velocity 
$1(U)$. After integration, Eq (11) can be proposed to link the distance travelled $(H)$ by a spherical

2 droplet in a gas to the dissolved concentration of the solute of interest $C_{j, H}^{L}$ :

$$
\boldsymbol{C}_{\boldsymbol{j}, \boldsymbol{H}}^{L}=C_{j, H}^{L, *}-\left(C_{j, 0}^{L, *}-C_{j, 0}^{L}\right) \exp \left(-k_{L} a \frac{H}{U}\right)
$$

4 The gas phase composition is considered constant. This was assumed because the spray was not

5 confined, since spraying was performed in ambient air. In fact, the concentration of ozone in air is

6 negligible (20 to $40 \mathrm{ppb})$ compared to the dissolved concentrations considered $(1.9 \mathrm{mg} / \mathrm{L})$.

7 Moreover, the amount of ozone transferred is diluted in the air so no accumulation of ozone in the

8 gas phase is expected. Thus, for ozone gas concentration: $C_{O_{3}, 0}^{G}=C_{O_{3}, H}^{G}=0 \rightarrow C_{O_{3}, 0}^{L, *}=C_{O_{3}, H}^{L, *}=0$.

9 Considering the case of dioxygen absorption, the $\mathrm{O}_{2}$ concentration in air is around $250 \mathrm{~g} / \mathrm{m}^{3}$ if $\mathrm{O}_{2}$ is

10 assumed to make up $21 \%$ of the air by volume. For this reason, any change of dioxygen gas

11 concentration in the air, caused by absorption by a liquid is expected to be insignificant. So it is

12 assumed that $C_{O_{2}, 0}^{G}=C_{O_{2}, H}^{G} \rightarrow C_{O_{2}, 0}^{L, *}=C_{O_{2}, H}^{L, *}$. These hypotheses lead to equations 12 and 13 for the

13 prediction of dissolved ozone in spherical droplets after a distance $H$ travelled in a gas and for

14 dissolved dioxygen, respectively:

$$
C_{\mathrm{O}_{3}, H}^{L}=C_{O_{3}, 0}^{L} \exp \left(-k_{L} a \frac{H}{U}\right)
$$

$$
C_{O_{2}, H}^{L}=C_{O_{2}, H}^{L, *}-\left(C_{O_{2}, 0}^{L, *}-C_{O_{2}, 0}^{L}\right) \exp \left(-k_{L} a \frac{H}{U}\right)
$$

b. $\mathrm{k}_{\mathrm{L}}$ correlation

19 Latter equations only relied on mass balances between phase, most of the work of prediction consist in choosing the convenient correlation for the term $k_{L}$. Correlations are commonly proposed depending on the geometry of the gas-liquid contactor used. 
1 Studies about mass transfer in spraying column usually provide correlations based on

2 dimensionless numbers such as [27]:

$$
S h=\frac{k_{L} d}{D_{A B}}=\omega \operatorname{Re}^{\gamma} S c^{\beta}
$$

4 Where the parameters $\omega, \gamma, \beta$ are experimentally determined. Global measurements in the system

5 led to values of $1 / 2$ for the dimensionless numbers exponents, and $\omega$ can be taken as 0.8 . Then

6 from the hydrodynamics parameters $U$ and $d$, the $k_{L}$ can be determined and implemented in eq(12)

7 and eq (13) to predict the concentration evolution of solute in the liquid. Those correlations are

8 slightly different between studies and discrepancies of predictions can be found.

9

Results and discussion

$12 \quad I$ - Mass transfer identification and overall characterization

13

14

1) Hydrodynamic of the spray

15 Using the methodology developed in section 4), diameters and velocities of the droplets have been

16 assessed for two nozzles: the ADX nozzle with air suction and the AFX nozzle without air suction.

17 An exemple of diameters distribution for the ADX nozzle is shown in Fig.3. 


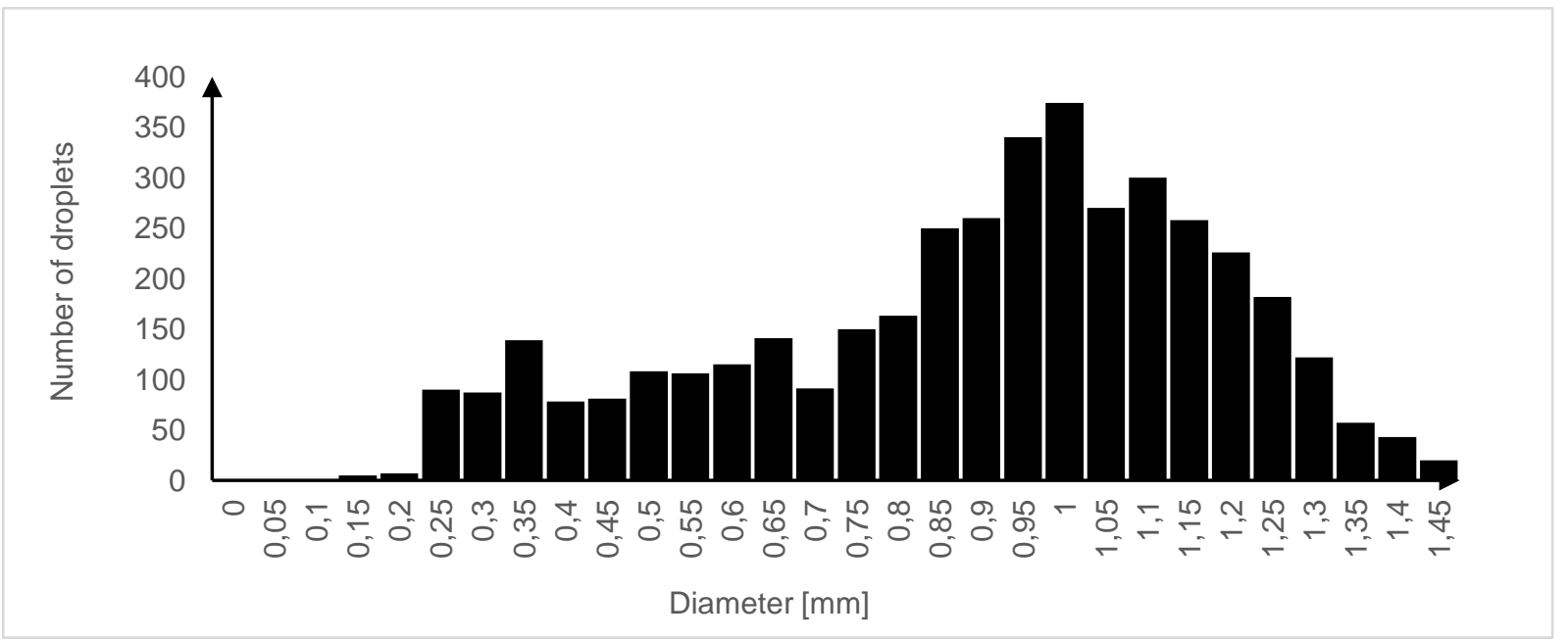

1

Fig.3. Hydrodynamics data: droplets diameters (left) for the ADX nozzle

3 Velocities and diameters obtained by the hydrodynamic study are regrouped in Table 1. It also

4 contains the Reynolds number of the droplets and the residence time of the liquid in the system.

5 The residence time has been assessed regarding the height of the system: $0.8 \mathrm{~m}$. The interfacial

6 area offered by the droplets is also presented.

7 Using the front and side view of the liquid film issuing the nozzle as shown in Fig 4, length $L$, width

$8 \quad l$ and the thickness $\delta$ are directly measured on the pictures. Then, the interfacial area proposed by

9 this film is determined for each nozzle. 


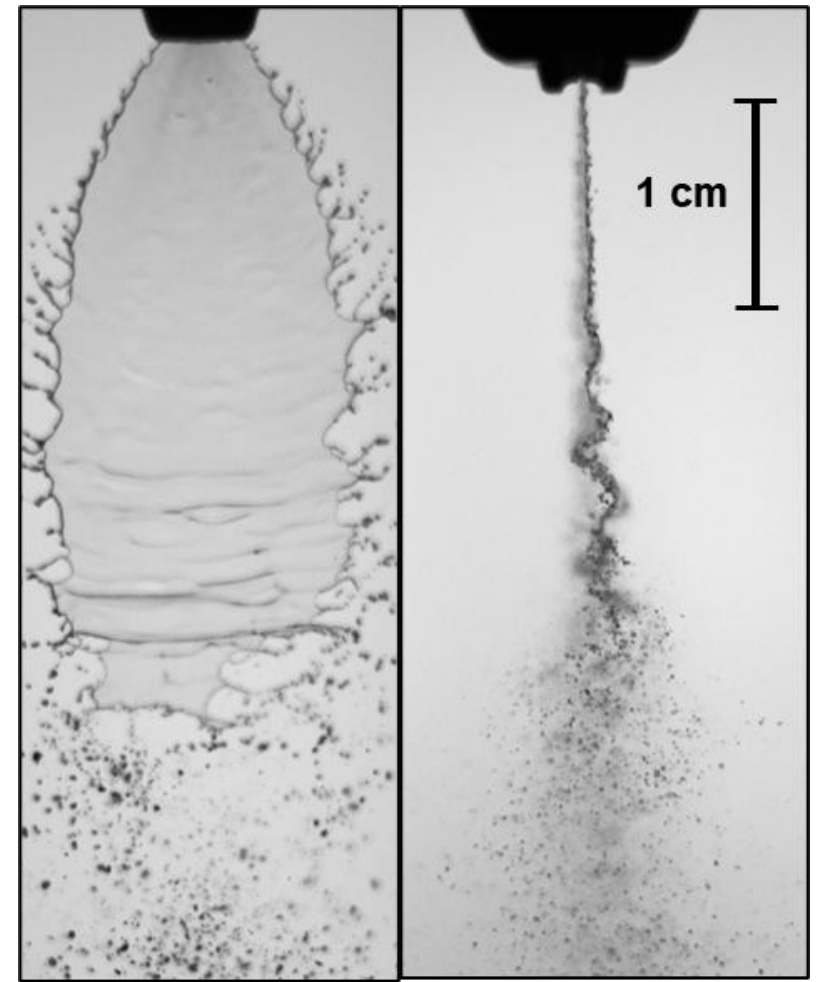

Fig 4. Front (left) and side (right) view of the liquid film issuing the AFX nozzle

\begin{tabular}{|c|c|c|}
\hline & $A D X$ & $A F X$ \\
\hline$U(\mathrm{~m} / \mathrm{s})$ & 3.9 & 8.5 \\
\hline$d(\mathrm{~m})$ & $1.01 E-3$ & $6.00 E-4$ \\
\hline $\boldsymbol{\tau}(\mathrm{s})$ & 0.205 & 0.094 \\
\hline $\boldsymbol{R}_{\text {droplet }}$ & 3939 & 5100 \\
\hline$L(\mathrm{~m})$ & 0.02 & 0.03 \\
\hline $\boldsymbol{l}(\mathrm{m})$ & 0.015 & 0.015 \\
\hline$\delta(\mu \mathrm{m})$ & 300 & 150 \\
\hline $\boldsymbol{a}_{\text {droplets }}\left(\mathrm{m}^{2} / \mathrm{m}^{3}\right)$ & 5940 & 10000 \\
\hline $\boldsymbol{a}_{\text {film }}\left(\mathrm{m}^{2} / \mathrm{m}^{3}\right)$ & 7022 & 13600 \\
\hline $\boldsymbol{a}_{\text {droplets }}^{\mathbf{0}}\left(\mathrm{m}^{2} / \mathrm{m}^{\mathbf{3}}\right)$ & 0.61 & 0.47 \\
\hline $\boldsymbol{a}_{\text {film }}^{\mathbf{0}}\left(\mathrm{m}^{2} / \mathrm{m}^{3}\right)$ & $0.20(\mathrm{H=10 \textrm {cm } )}$ & $0.29(\mathrm{H=10} \mathrm{cm})$ \\
& $0.025(\mathrm{H=80} \mathrm{cm})$ & $0.036(\mathrm{H=} 80 \mathrm{~cm})$ \\
\hline
\end{tabular}


1 The ADX nozzle produce larger droplets with lower velocities $(1.01 \mathrm{~mm}-3.9 \mathrm{~m} / \mathrm{s})$ than the AFX

2 nozzle $(0.6 \mathrm{~mm}-8.5 \mathrm{~m} / \mathrm{s})$. The air suction is responsible of this difference. The difference of

3 velocities leads to different residence times, the droplets produced by the ADX spends more time

4 in contact with the air during their travel in the system $\left(\tau_{A D X}=0.2 s-\tau_{A F X}=0.1 s\right)$.

5 The thickness $\delta$ of the liquid film is overestimated. As shown in Fig 4, the edges of the liquid film

6 are thicker than the body of the liquid film. Then by measuring the thickness from the sideview, the

7 thickness of the edges is measured and not the thickness of the body of the film.

8 The interfacial area per volume of liquid estimated for the liquid film is higher than the one

9 assessed for the droplets. In the case of the AFX nozzle, the interfacial area of the film $a_{\text {film }}$ is

10 around $13600 \mathrm{~m}^{-1}$ where the one of the droplets $a_{\text {droplets }}$ is only $10000 \mathrm{~m}^{-1}$. The thickness

11 reached by the liquid film is relatively small compared to the diameter of the droplets. The kinetic

12 energy of the liquid film overcomes the surface tensions forces to develop a high surface of liquid

13 compared to its volume.

14 However, the interfacial assessed per volume of contactor $a_{f i l m}^{0}$ shows that the surface offered by

15 the liquid film is lower than the one of the droplets $a_{\text {droplets }}^{0}$ In fact, the liquid film represents only a

16 small part of the system, it is present only in the 3-first $\mathrm{cm}$ after the nozzle. It is quickly atomized in

17 droplets, which is the goal of the process of spraying. Then the efficient interfacial area of the liquid

18 film region is not representative of the contactor, where most of the volume is occupied by droplets,

19 but it represents more than half of the droplet interfacial area when we consider the first $10 \mathrm{~cm}$

20 after the nozzle.

2) Dissolved concentrations profiles 
For both desorption and absorption experiments, the concentration of the solute is plotted versus

2 the distance of liquid collection from the nozzle in Fig.5. Both nozzles were tested for each
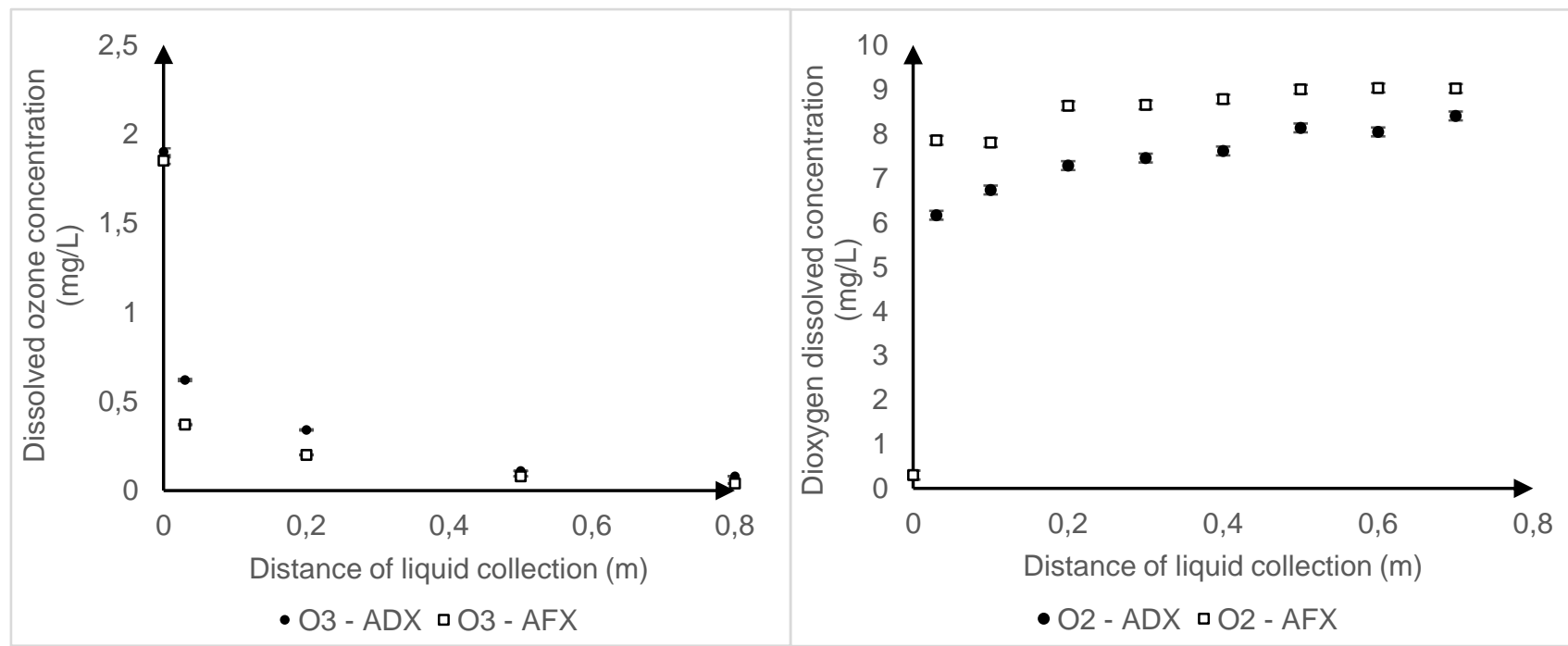

condition (desorption and absorption).

Fig.5. Concentration profiles for ozone desorption (left) and dioxygen absorption (right)

7 Dissolved concentration profiles exhibited a common behaviour: the first concentration, measured

$83 \mathrm{~cm}$ after the nozzle, was markedly different from the concentration prepared initially. The concentration of dissolved $\mathrm{O}_{3}$ fell from 1.9 to $0.62 \mathrm{mgO}_{3} / \mathrm{L}$ and the concentration of dissolved $\mathrm{O}_{2}$

10 increased from 0.3 to $6.16 \mathrm{mgO}_{2} / \mathrm{L}$ within the 3 centimetres after the ADX nozzle orifice. This 11 concentration variation is sizeable compared to that in the rest of the spray. Within the $77 \mathrm{~cm}$ after 12 the first concentration measurement, the concentration variation was less pronounced. In fact, the dissolved ozone concentration decreased from 0.62 to $0.08 \mathrm{mgO}_{3} / \mathrm{L}$ while the $\mathrm{O}_{2}$ concentration rose from 6.16 to $8.4 \mathrm{mgO}_{2} / \mathrm{L}$ in the remaining distance of the spray produced by the ADX nozzle.

3) Estimation of the extent of ozone loss by decomposition

17 Considering a kinetic constant of first order with respect to ozone, the decrease of dissolved ozone due to decomposition during the travel of the liquid in the spray $\left(\tau_{A D X}=0.2 s\right)$ is estimated with Eq (1). It is compared in Fig 6 with the above experimental ozone depletion obtained. 


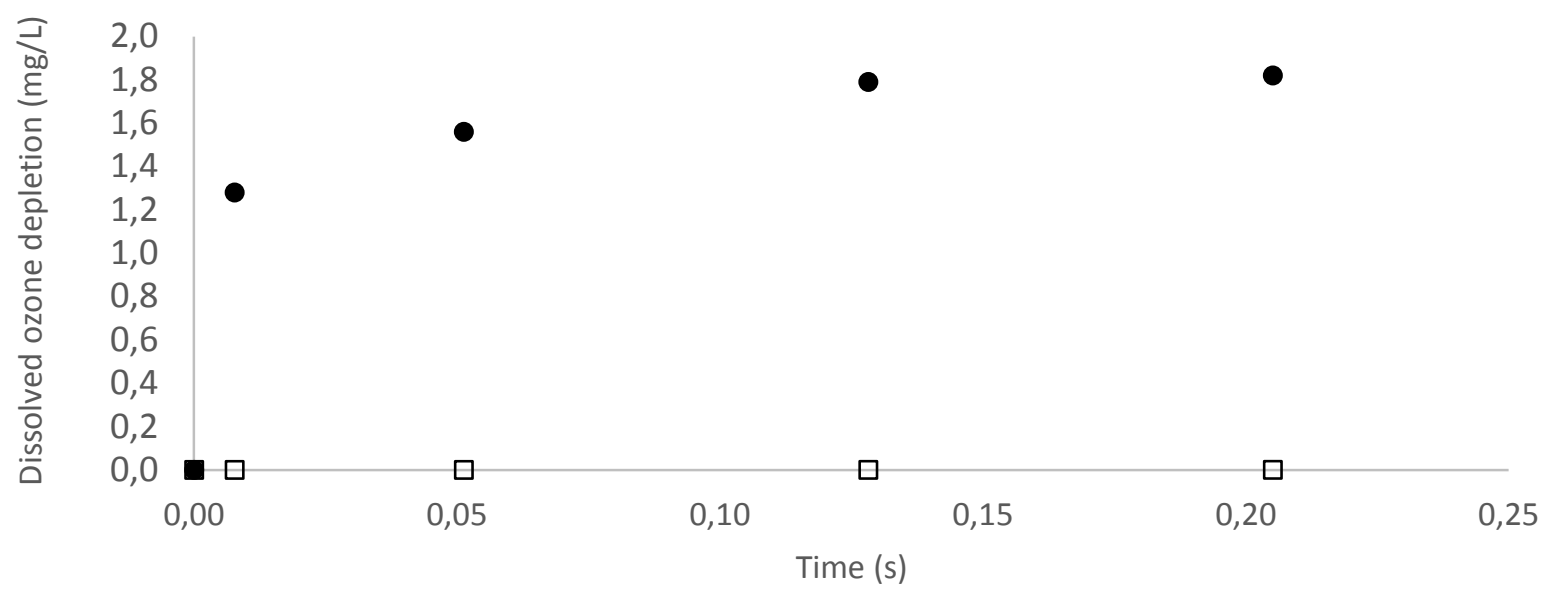

2 Fig 6. Experimental ozone depletion (circle) compared to the estimated depletion by reaction (square) along the spray

5 The variation of ozone due to decomposition is negligible compared to the experimental variations

6 measured. The low residence time $(0.2 \mathrm{~s})$ integrated for this estimation is responsible of such a

7 difference. Although the decomposition of ozone is a non-negligible phenomenon in the common

8 applications of ozone, the time scale considered here is too small to observe any sensitive

9 variation due to self-decomposition of ozone. From there, the variation observed in the liquid phase 10 can be associated to a mass transfer mechanism.

4) Mass transfer description

13 This difference of variation between experimental results and decomposition estimation indicates 14 that a strong mass transfer occurred in the first centimetres after the nozzle. In contrast, for the remaining distance of the spray, the mass transfer was lower.

16 As the values of equilibrium concentrations $\left(C^{L, *}\right)$ are different for ozone and dioxygen, the 17 dissolved concentration variations obtained are not numerically comparable between $\mathrm{O}_{3}$ and $\mathrm{O}_{2}$. To 18 better compare those solute variations, the approach to equilibrium parameter allows to normalize 19 the results: 
Approach to equilibrium - desorption $=\frac{\Delta C_{\exp }}{\Delta C_{\max }}=\frac{C_{O_{3}, i}^{L}-C_{O_{3}, f}^{L}}{C_{O_{3}, i}^{L}-C_{O_{3, f}}^{L, *}}$

Approach to equilibrium - absorption $=\frac{C_{O_{2, f}}^{L}-C_{O_{2}, i}^{L}}{C_{O_{2, f}}^{L, *}-C_{O_{2}, i}^{L}}$

$E q(15),(16)$

5 A striking feature of Fig.7 is that the curves increase at the same rate. Solute variations between

6 measurements are strong at the outlet of the nozzle but are less pronounced in the remaining

spray. For the ozone desorption, the concentration measured $3 \mathrm{~cm}$ after the nozzle is about $70 \%$ of

8 the theoretical concentration at equilibrium. The same approach to equilibrium is observed for the

dioxygen absorption performed with the same ADX nozzle. Moreover, the liquid tends to reach the equilibrium concentration imposed by Henry's law. After $70 \mathrm{~cm}$ travelled in air, around $90 \%$ of the theoretical concentration is reached. This means that, although the theoretical concentration was not completely reached within the distance considered, the gas-liquid system was driven to an equilibrium determined by mass transfer.

Hence it is possible to conclude that mass transfer is the phenomenon at the origin of solute transport in and out of the droplets as the same behaviour is observed for ozone desorption and

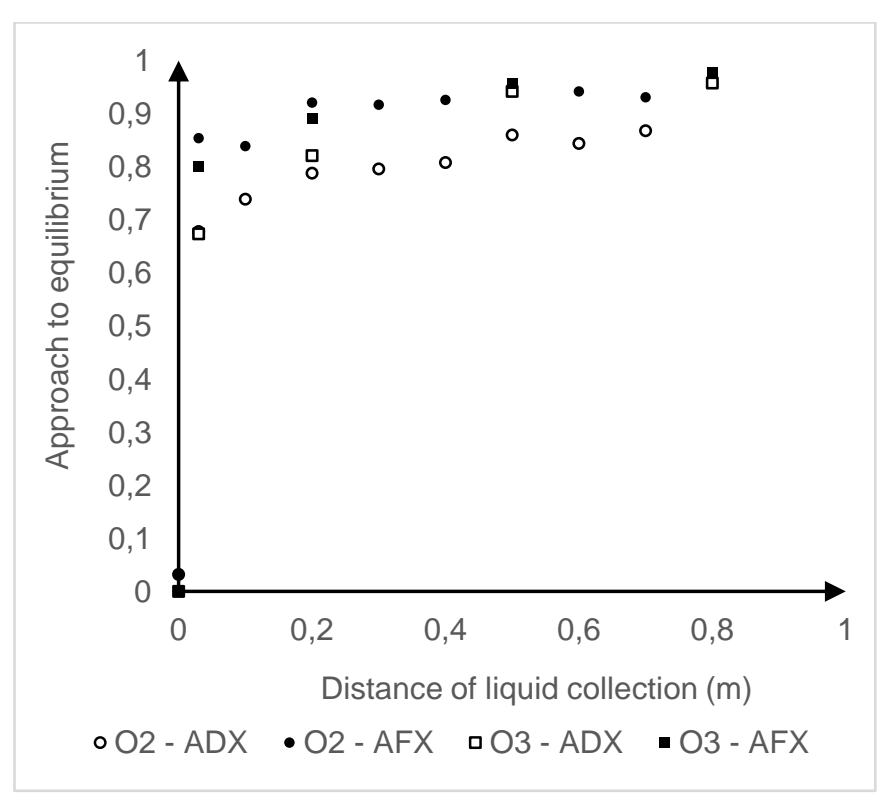

Fig.7. Approach to equilibrium along the spraying distance 
oxygen absorption. Therefore, the autolysis phenomenon proposed by Fujiwara et al [33] is not responsible for the disappearance of ozone in droplets. The ozone loss observed during spraying

3 is due to diffusion described by the mass transfer theories.

4 In addition, this also explains why the spraying of ozonated water does not constitute an efficient

5 surface treatment, as shown by the studies of Spotts et al. [17], Chawla et al. [18] and Ebihara et 6 al. [19]. Spraying ozonated water leads to a dissolved concentration $60 \%$ lower than the initial concentration prepared being obtained a few centimetres after the atomizer. Thus, the dose of ozone applied is not the expected one. A significantly better treatment effect was obtained on

9 shrimps and pears by immersing them in ozonated water rather than spraying it. For pest 10 management, the results when spraying close to the target $(2 \mathrm{~cm})$ were acceptable because, at 11 this distance, even though a considerable proportion of the ozone is lost by mass transfer, the remaining ozone (around 30\%) should be enough for the treatment.

Experiments performed in the present study also revealed that two kinds of transfer regime seem to drive the mass transfer in a spray. A first area is located within the first few centimetres after the atomizer (from 0 to $3 \mathrm{~cm}$ ) where the transfer rate is relatively strong. This region is characterized by a consequent gas-liquid exchange where around $70 \%$ of the transfer occurs. A second region

17 corresponds to a transfer that is less pronounced after the $3 \mathrm{~cm}$ from the atomizer orifice. Images 18 taken in a window of $50 \mathrm{~cm}^{2}$ after the atomizer show that these two regions seem to correspond to 19 different liquid formation stages in the spray. The first region would correspond to the liquid film 20 leaving the nozzle before droplets are torn apart. The surface area of this film and its 21 hydrodynamics would permit significantly better mass transfer compared to the second region. The 22 latter would correspond to the part of the spray where droplets are formed, and this configuration 23 seems to offer weaker conditions for the transfer. Fig.8 shows the two regions considered. 
Region I: Liquid film

the two regions.

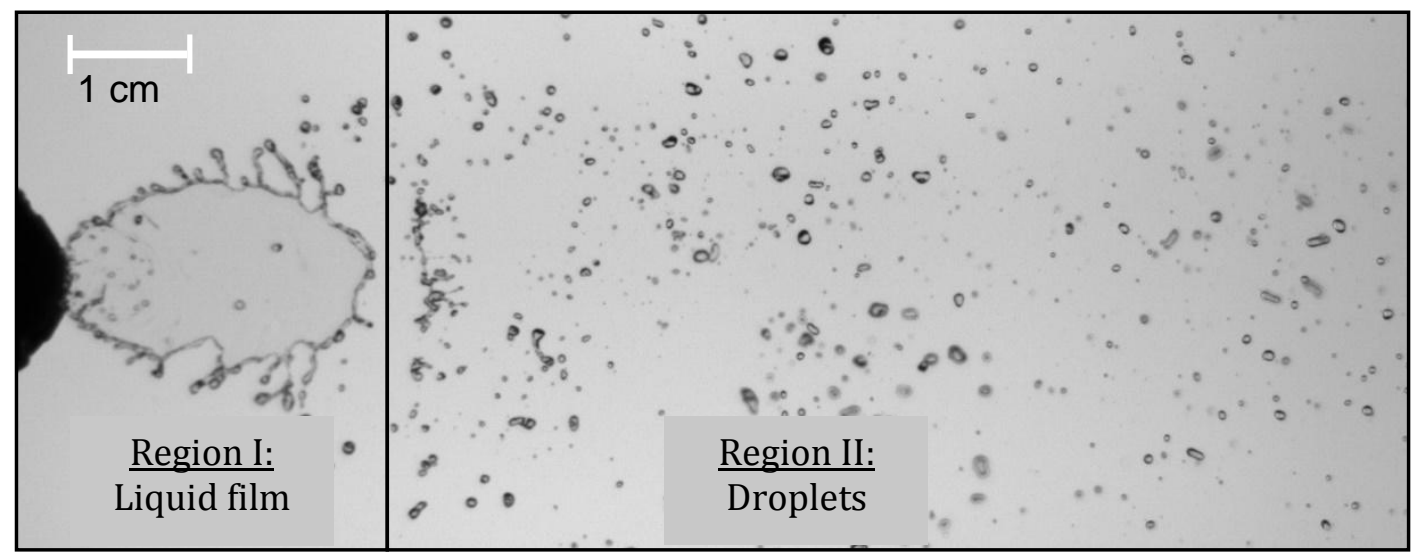

Fig.8. Image taken from the spray and its two different liquid formation stages - ADX nozzle $-45 L / h$

3 To better characterize these two areas, a quantification of the transfer in each region is proposed

from measurements of the dissolved concentrations. This characterization based on the volumetric

mass transfer coefficient calculation would highlight the extent of the difference of transfer between

8 5) Determination of overall volumetric mass transfer coefficient

9 The efficiency of the transfer is commonly characterized by the volumetric mass transfer coefficient $k_{L} a\left(\mathrm{~s}^{-1}\right)$. From Eq (9), the following expression is used to determine this coefficient:

$$
\ln \frac{\left(C_{j, i}^{L, *}-C_{j, i}^{L}\right)}{\left(C_{j, o}^{L, *}-C_{j, o}^{L}\right)} \frac{U}{H}=k_{L} a
$$

13 By taking $H$ as $3 \mathrm{~cm}$ and considering the corresponding dissolved concentrations, a $\left(k_{L} a\right)_{\text {film }}$ was 14 determined for the liquid film region. The $\left(k_{L} a\right)_{\text {droplets }}$ associated with the droplet region was 15 calculated by taking $H$ as $77 \mathrm{~cm}$ (from $3 \mathrm{~cm}$ to $80 \mathrm{~cm}$ ) with the respective dissolved concentrations. An averaged value of the volumetric mass transfer coefficient $\overline{k_{L} a}$ was also assessed along the whole spray (from 0 to $80 \mathrm{~cm}$ ). Velocities obtained by image analysis for each nozzle were assumed constant for the whole spray. For both the absorption and the desorption configuration, this gives: 


\begin{tabular}{|c|c|c|c|c|}
\hline & \multicolumn{2}{|c|}{ ADX } & \multicolumn{2}{|c|}{ AFX } \\
\hline Solute & $\mathrm{O}_{2}$ & $\mathrm{O}_{3}$ & $\mathrm{O}_{2}$ & $\mathrm{O}_{3}$ \\
\hline$a_{\text {droplets }}\left(\frac{m^{2}}{m^{3}}\right)$ & \multicolumn{2}{|c|}{5940} & \multicolumn{2}{|c|}{10000} \\
\hline$a_{f i l m}\left(\frac{m^{2}}{m^{3}}\right)$ & \multicolumn{2}{|c|}{7022} & \multicolumn{2}{|c|}{13600} \\
\hline$\overline{k_{L} a}\left(s^{-1}\right)$ & 10.92 & 15.44 & 32.07 & 40.73 \\
\hline$\left(k_{L} a\right)_{\text {droplets }}\left(s^{-1}\right)$ & 4.82 & 10.37 & 8.84 & 24.55 \\
\hline$\left(k_{L} a\right)_{f i l m}\left(s^{-1}\right)$ & 147.16 & 145.58 & 550.83 & 456.01 \\
\hline$\overline{k_{L}}\left(\frac{m}{s}\right)$ & $1.84 .10^{-3}$ & $2.60 .10^{-3}$ & $3.21 .10^{-3}$ & $4.07 .10^{-3}$ \\
\hline$\left(\boldsymbol{k}_{L}\right)_{\text {droplets }}\left(\frac{\boldsymbol{m}}{\boldsymbol{s}}\right)$ & $8.11 .10^{-4}$ & $1.75 .10^{-3}$ & $8.84 .10^{-3}$ & $2.455 .10^{-3}$ \\
\hline$\left(\boldsymbol{k}_{L}\right)_{\text {film }}\left(\frac{\boldsymbol{m}}{\boldsymbol{s}}\right)$ & $2.1 .10^{-2}$ & $2.1 .10^{-2}$ & $4.10 .10^{-2}$ & $3.35 .10^{-2}$ \\
\hline
\end{tabular}

Table 2. Calculation of the volumetric mass transfer coefficient for different atomizers and regions of the spray using Eq (17)

3 The results in Table 2 show that the transfer occurring in the first centimetres after the nozzle exit

4 is considerably higher than in the rest of the spray. It is possible to state that, since the

$5 \quad\left(k_{L} a\right)_{\text {film }}$ obtained by considering only the $3 \mathrm{~cm}$ after the atomizer $\left(550.83 \mathrm{~s}^{-1}\right)$ for dioxygen 6 absorption with AFX nozzle is significantly greater than the

$7 \quad\left(k_{L} a\right)_{\text {droplets }}$ obtained by considering the rest of the spray $\left(8.84 \mathrm{~s}^{-1}\right)$. This behaviour was observed

8 for both solutes and for each nozzle. The considerable difference of values for the volumetric mass

9 transfer coefficient in both regions confirms the presence of the two regimes of transfer in the 10 spray. This considerable rate of transfer in the first few centimetres has been reported by several 11 studies [34-36]. Although they highlighted significantly higher transfer close to the nozzle, no 12 efforts were made to characterize this region since, for most of the spraying column, it represents a 13 negligible part of the gas-liquid system.

14 The transfer improvement in the first region could be explained by the surface available for the 15 exchange. From the estimations of interfacial area performed, it seems that the liquid film offers 16 considerable surface per volume of liquid compared to droplets. Moreover, as observed in many 
studies, the liquid film undergoes instabilities that lead to surface deformation and an increased

2 surface area with respect to a simple laminar flat film where transfer is commonly limited $[37,38]$.

3 These instabilities have been identified as increasing waves in our side-view pictures as shown in

4 Fig 4. The interfacial area of the film calculated was assuming a rectangular prism, without taking

5 into consideration those waves that increase the surface of the film. In other words, the higher

6 interfacial area reached by the liquid film could be a reasonable phenomenon to explain the high

7 mass transfer measured in this region.

8 This difference of regime observed may also be explained by better hydrodynamics conditions in

9 the liquid film, enhancing the frequency of contact of "fresh" elements of fluid with the gas phase.

10 Thus, compared to droplets, where internal circulation can be limited depending on droplet size,

11 the liquid film would offer better renewal of the liquid layer in contact with the gas phase (due to its 12 high liquid velocities) and thus favour for solute exchanges.

13 To have an idea of the extent of the contribution of the surface effects and the hydrodynamics 14 effects on the mass transfer enhancement, the $k_{L}$ was assessed. The experimental $k_{L}$ determination was performed by dividing the $k_{L} a$ by the interfacial area $a$. This was done using the hydrodynamic analysis performed for the spray.

17 Liquid side mass transfer coefficients for the droplet region $\left(k_{L}\right)_{\text {droplets }}$ are actually close to data 18 found in the literature $[36,39]$, so it is possible to conclude that the transfer determined for the 19 second part of the spray (after the droplet formation stage) corresponds to the exchange of a 20 solute between the liquid droplets and a gaseous phase. This also means that the volumetric mass 21 transfer coefficient calculated for the liquid sheet is consistent with the method of measurement.

22 The values obtained for the $\left(k_{L}\right)_{\text {film }}$ were considerably higher than those of droplets. Then the 23 surface effects are not only responsible of the mass transfer improvement, but the hydrodynamic 24 that occurs in the liquid film seems to promote the diffusion of solute molecules through the liquid 25 interface.

26 However, the determination of the interfacial area of the liquid film was an estimation especially for 27 its thickness, and the concentrations measured were not representative of the exact boundaries of 
1 the liquid film due to the method of collection used. In this way, a deeper study to characterize the

2 liquid film region would confirm whether the difference of transfer between the two regions was due

3 to a better interfacial area being produced by the liquid film or by better hydrodynamic conditions

$4 \quad$ inside it (very high liquid velocities) or by both.

5

$6 \quad 6)$ Model application

7 A model has been developed to predict the concentration of solute dissolved in the droplets along

8 the distance travelled in the gas phase. The model uses a $k_{L}$ calculated from correlation obtained

9 by overall characterization of the spray. This $k_{L}$ is calculated from the mean diameter and the 10 mean velocity determined previously by the hydrodynamic study. Fig.9 illustrates the application of 11 this model for the ozone desorption and dioxygen absorption experiments.

12
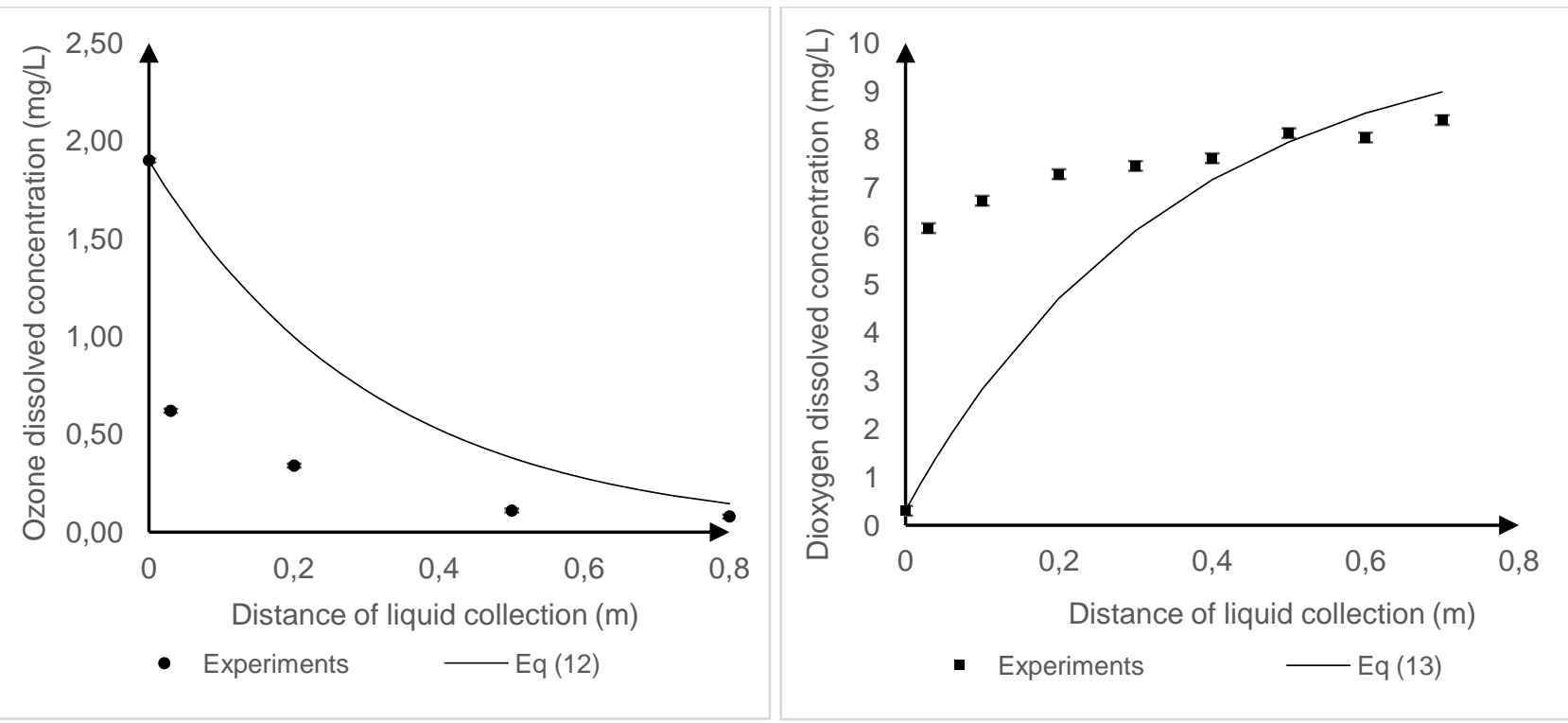

Fig.9. Ozone (left) and dioxygen (right) dissolved concentration profiles and their applied models

The comparison with the experimental data shows a good trend but the fitting does not reach good quality even though the overall fitting from $\mathrm{H}=0$ to $\mathrm{H}=0.8$ agrees with the final dissolved concentration change. 
The main source of error between the model and the experimental data might be due to the strong

2 exchanges that occur after the nozzle outlet, into the film, where droplets are still not formed. The

3 model is suitable for spherical particles such as droplets but not for a geometry such as the liquid

4 film. For this reason, $\mathrm{Eq}(13)$ is applied to the part of the spray where droplets are formed. This is

5 done by considering the initial concentration of the model as the concentration measured at $3 \mathrm{~cm}$

6 after the nozzle: $C_{j, \mathrm{H}=0}^{L}=C_{j, \mathrm{H}=0.03}^{L}$. This correction leads to a much better fit, especially for the

$7 \quad$ ozone experiments as shown in Fig. 10.

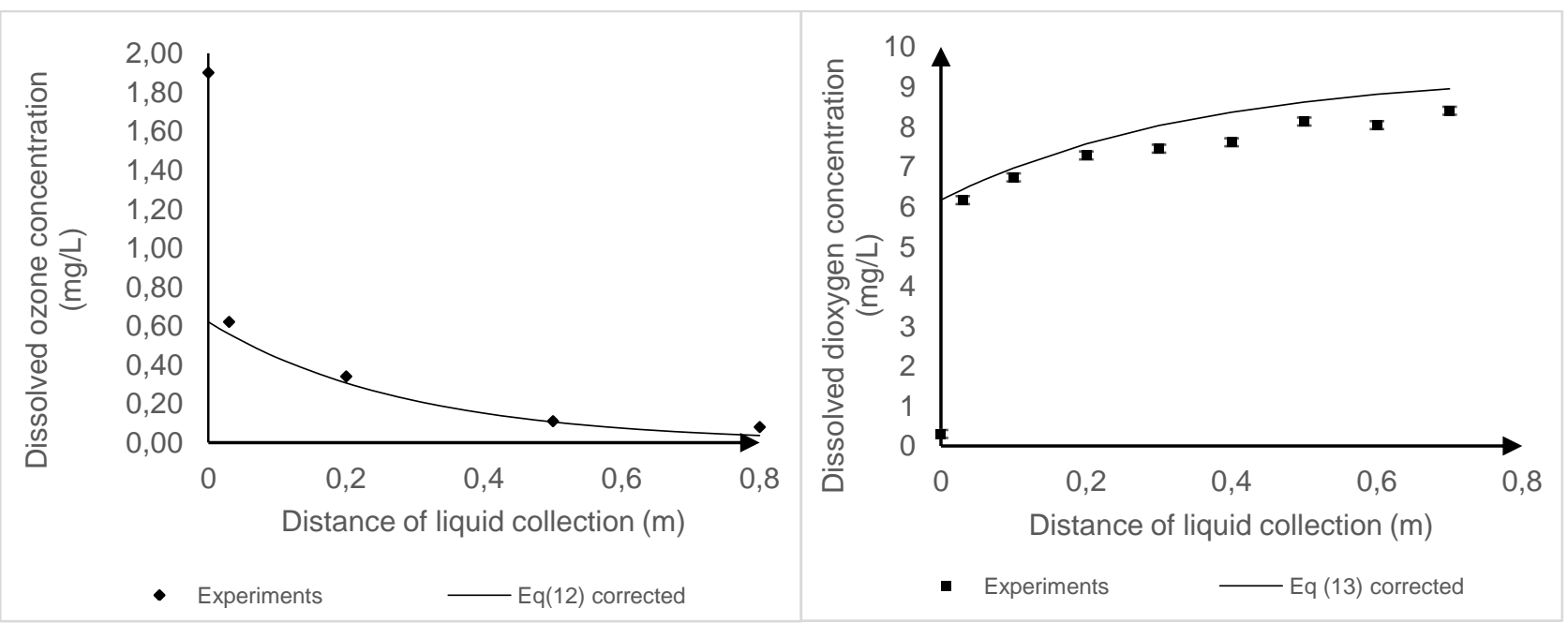

Fig.10. Model application for the droplets region in the spray for ozone desorption (left) and dioxygen absorption (right)

This correction highlights the fact that the overall correlation used is suitable for droplets but cannot be applied for the film region to model the mass transfer. Lack of method to characterize the liquid film does not allow us to provide a correlation for this region in the present study. Further study of the liquid film would figure out relevant parameters to predict the mass transfer in this region.

16 From the model developed, suggestions for avoiding ozone loss during spraying can be proposed.

17 First, a nozzle that produces large droplets should be preferred. It reduces the interfacial area 18 available for solute exchange. However, the kind of applications for pulverization can introduce some limits. For example, in agriculture droplets larger than $1 \mathrm{~mm}$ will not remain attached to the leaves of the plants, so the treatment will not be efficient. Another way of reducing ozone loss is to use a nozzle producing droplets with low velocities. High values of concentration saturation are 
reached much faster in the case of the AFX nozzle than with the ADX. Diameters and velocities of

2 the droplets produced by the AFX nozzle are more suitable for processes requiring high mass

3 transfer rate such as gas depollution, where an ADX nozzle is more appropriate to limit the mass

4 transfer, for surface disinfection by ozone for example. Finally, spraying ozonated water close to

5 the target (around $3 \mathrm{~cm}$ away) conserves a small amount of dissolved ozone for treatment, but the

6 surface coverage of the spray should remain limited.

7

8 


\section{Conclusions}

2 An experimental study has been conducted to identify the phenomenon that causes the loss of

3 dissolved ozone in droplets when ozonated water is sprayed. Mass transfer between liquid droplets

4 and the ambient air is responsible for these ozone losses. It occurs because the ozone dissolved in

5 the droplets is much more concentrated than the saturation concentration in air, which it is naturally

6 low. The phenomenon has been identified on the one hand, through performing desorption of ozonated water by spraying an ozone-rich liquid in ambient air and, on the other hand, by assessing the absorption of dioxygen from air in dioxygen-free water. Concentration profiles have

9 been compared and show a significantly similar trend: about $60 \%$ to $70 \%$ of the transfer is 10 achieved within the first few centimetres after the outlet of the nozzle. We have shown that ozone 11 self-decomposition kinetics were not able to explain the experimental concentration variation obtained into the droplets. The decrease of dissolved ozone in the liquid is then only caused by mass transfer phenomenon.

14 From mass balances and mass transfer theories, a model has been constructed to predict the dissolved concentration along the spraying distance. The calculation requires the droplet diameters and velocities in the system to be known. These hydrodynamic parameters were determined by

17 particle image analysis, and averaged values have proved suitable to provide an accurate fit with 18 the experimental data. The model exhibits discrepancies in the centimetres of the spray near the nozzle, which can be explained by the presence of a liquid film that is not yet atomized into droplets in this region. Thus, the model considering spherical droplets cannot be applied. Then, the model has been applied to the droplets part of the spray and provide a reasonable prediction of the solute variation. Further study of the liquid film would allow the mass transfer in this region to be predicted. Interface sizing and local measurements of the solute in the liquid film would confirm if

24 the high mass transfer reached there is due to surface enhancement and/or improvement in the 25 hydrodynamics conditions.

\section{Acknowledgments}


This research belongs to the SOLSTICE project supported by the French state within the

2 framework of "Programme d'Investissements d'Avenir".

\section{References}

6 [1] C. O'Donnell, B.K. Tiwari, P.J. Cullen, R.G. Rice, Ozone in Food Processing, Wiley-Blackwell,

[2] The Royal Society, Ground-level Ozone in the 21st Century: Future Trends, Impacts and Policy Implications, 2008. http://www.royalsociety.org/Ground-level-ozone-in-the-21st-century-future-trendsimpacts-and-policy-implications-/. Oxford, UK, 2012. https://doi.org/10.1002/9781118307472.

R. Tatin, L. Moura, N. Dietrich, S. Baig, G. Hébrard, Physical absorption of volatile organic compounds by spraying emulsion in a spray tower: Experiments and modelling, Chem. Eng. Res. Des. 104 (2015) 409-415. https://doi.org/10.1016/j.cherd.2015.08.030.

4] S. Baig, P. Mouchet, Oxydation et réduction appliquées au traitement de l'eau Ozone - Autres oxydants - Oxydation avancée - Réducteurs, Tech. l'ingénieur Procédés Trait. Des Eaux Potables, Ind. Urbaines. w2702 (2010).

[5] T. Batakliev, V. Georgiev, M. Anachkov, S. Rakovsky, S. Rakovsky, Ozone decomposition, Interdiscip. Toxicol. 7 (2014) 47-59. https://doi.org/10.2478/intox-2014-0008.

[6] R. Mittler, ROS Are Good, Trends Plant Sci. 22 (2017) 11-19. https://doi.org/10.1016/j.tplants.2016.08.002.

[7] R. Mittler, S. Vanderauwera, N. Suzuki, G. Miller, V.B. Tognetti, K. Vandepoele, M. Gollery, V. Shulaev, F. Van Breusegem, ROS signaling: the new wave?, Trends Plant Sci. 16 (2011) 300-309. https://doi.org/10.1016/j.tplants.2011.03.007.

[8] P.D. Ray, B.-W. Huang, Y. Tsuji, Reactive oxygen species (ROS) homeostasis and redox regulation in cellular signaling, Cell. Signal. 24 (2012) 981-990. https://doi.org/10.1016/j.cellsig.2012.01.008.

[9] N. SUZUKI, S. KOUSSEVITZKY, R. MITTLER, G. MILLER, ROS and redox signalling in the response of plants to abiotic stress, Plant. Cell Environ. 35 (2012) 259-270. https://doi.org/10.1111/j.1365-3040.2011.02336.x.

[10] I.R. Komanapalli, B.H.S. Lau, Ozone-induced damage of Escherichia coli K-12, Appl. Microbiol. Biotechnol. 46 (1996) 610-614. https://doi.org/10.1007/s002530050869. 
[11] J. KANGASJARVI, J. TALVINEN, M. UTRIAINEN, R. KARJALAINEN, Plant defence systems induced by ozone, Plant, Cell Environ. 17 (1994) 783-794. https://doi.org/10.1111/j.13653040.1994.tb00173.x. H. Steffen, R.G. Rice, The PhytO3 Tech Crop Protection Technology - Trial Results in a 2,700 ha $(6,500$ acre) Soy Farm in Brazil, Ozone Sci. Eng. 30 (2008) 210-215. https://doi.org/10.1080/01919510801951027.

[13] H. Steffen, R.G. Rice, The PhytO3 Tech Crop Protection Technology for Microorganism and Insect Control using Ozone, UV, and Dipole-Electrical Air Jet Spray Technologies - Technical Basis and Possible Chemistries Involved, Ozone Sci. Eng. $30 \quad$ (2008) 216-227. https://doi.org/10.1080/01919510701864270.

[14] A.S. Moffat, Finding New Ways to Fight Plant Diseases, Science (80-. ). 292 (2001) 2270-2273. https://doi.org/10.1126/science.292.5525.2270.

[15] T. Graham, P. Zhang, Y. Zheng, M.A. Dixon, Phytotoxicity of Aqueous Ozone on Five Containergrown Nursery Species, HortScience. 44 (2009) 774-780. https://doi.org/10.21273/HORTSCI.44.3.774.

[16] K. Fujiwara, T. Fujii, Effects of Spraying Ozonated Water on the Severity of Powdery Mildew Infection on Cucumber Leaves, Ozone Sci. Eng. 24 (2002) 463-469. https://doi.org/10.1080/01919510208901635.

[17] R.A. Spotts, Effect of Ozonated Water on Postharvest Pathogens of Pear in Laboratory and Packinghouse Tests, Plant Dis. 76 (1992) 256. https://doi.org/10.1094/pd-76-0256.

[18] A. Chawla, J.W. Bell, M.E. Janes, Optimization of Ozonated Water Treatment of Wild-Caught and Mechanically Peeled Shrimp Meat, J. Aquat. Food Prod. Technol. 16 (2007) 41-56. https://doi.org/10.1300/J030v16n02_05.

[19] K. Ebihara, F. Mitsugi, T. Ikegami, N. Nakamura, Y. Hashimoto, Y. Yamashita, S. Baba, H.D. Stryczewska, J. Pawlat, S. Teii, T.L. Sung, Ozone-mist spray sterilization for pest control in agricultural management, EPJ Appl. Phys. 61 (2013) 1-5. https://doi.org/10.1051/epjap/2012120420.

[20] K. Fujiwara, T. Fujii, Research Note: Effects of Ozonated Water Spray Droplet Size and Distance on the Dissolved Ozone Concentration at the Spray Target, Ozone Sci. Eng. 26 (2004) 511-516. https://doi.org/10.1080/01919510490507892.

M. Tournois, M. Pages, M. Roustan, D. Kleiber, F. Violleau, G. Hébrard, Implementation of ozonated 
water pulverization: characterization of the ozone desorption, in: I.O. Association (Ed.), Int. Ozone Assoc. - B. Abstr. - 22nd World Congr. Exhib. - Barcelona, Barcelona, 2015: p. 7. https://doi.org/979-

[22] M. Roustan, Transferts gaz-liquide dans les procédés de traitement des eaux et des effluents gazeux, Ed. TEC\&DOC -Lavoisier. (2003) 800.

[23] L. Hegely, J. Roesler, P. Alix, D. Rouzineau, M. Meyer, Absorption methods for the determination of mass transfer parameters of packing internals: A literature review, AIChE J. 63 (2017) 3246-3275. https://doi.org/10.1002/aic.15737.

[24] H. Bader, J. Hoigné, Determination of ozone in water by the indigo method, Water Res. 15 (1981) 449-456. https://doi.org/10.1016/0043-1354(81)90054-3.

[25] K. Wongwailikhit, N. Dietrich, G. Hébrard, P. Painmanakul, Performance of a Monofiber Optical Probe in Determining the Droplet Size and Velocity in Spray Systems Compared with a High-Speed Camera, Ind. Eng. Chem. Res. (2019). https://doi.org/10.1021/acs.iecr.9b02446.

[26] E. Babinsky, P.E. Sojka, Modeling drop size distributions, Prog. Energy Combust. Sci. 28 (2002) 303-329. https://doi.org/10.1016/S0360-1285(02)00004-7.

[27] H. Amokrane, A. Saboni, B. Caussade, Experimental study and parameterization of gas absorption by water drops, AIChE J. 40 (1994) 1950-1960. https://doi.org/10.1002/aic.690401204.

[28] E. Lépinasse, M. Marion, S. Guella, S. Alexandrova, A. Saboni, Absorption et désorption du dioxyde de souffre par des gouttes d'eau de fort diamètre en chute. Sulfur dioxide absorption and desorption by large free falling water droplets, Rev. Des Sci. l'eau. 18 (2012) 5. https://doi.org/10.7202/705547ar.

[29] G.I. Kelbaliyev, Drag coefficients of variously shaped solid particles, drops, and bubbles, Theor. Found. Chem. Eng. 45 (2011) 248-266. https://doi.org/10.1134/S0040579511020084.

[30] E. Lépinasse, M. Marion, S. Guella, S. Alexandrova, A. Saboni, Absorption et désorption du dioxyde de souffre par des gouttes d'eau de fort diamètre en chute., Rev. Des Sci. l'eau. 18 (2005) 5-23. https://doi.org/10.7202/705547ar.

[31] R. Hariz, J.I. del Rio Sanz, C. Mercier, R. Valentin, N. Dietrich, Z. Mouloungui, G. Hébrard, Absorption of toluene by vegetable oil-water emulsion in scrubbing tower: Experiments and modeling, Chem. Eng. Sci. 157 (2017) 264-271. https://doi.org/10.1016/j.ces.2016.06.008.

[32] D. Gardoni, A. Vailati, R. Canziani, Decay of Ozone in Water: A Review, Ozone Sci. Eng. 34 (2012) 233-242. https://doi.org/10.1080/01919512.2012.686354. 
[33] K. Fujiwara, T. Fujii, Research note: Effects of ozonated water spray droplet size and distance on the dissolved ozone concentration at the spray target, Ozone Sci. Eng. 26 (2004) 511-516. https://doi.org/10.1080/01919510490507892.

4 [34] R.L. Pigford, C. Pyle, ENGINEERING AND PROCESS DEVEILOPMENT Performance

[36] S.G. Simpson, S. Lynn, Vacuum-spray stripping of sparingly soluble gases from aqueous solutions:

[35] W.-C. Lin, P.A. Rice, Y.-S. Cheng, A.J. Barduhn, Vacuum stripping of refrigerants in water sprays, AIChE J. 23 (1977) 409-415. https://doi.org/10.1002/aic.690230402.

10
Part I. Mass transfer from streams issuing from hydraulic nozzles, AIChE J. 23 (1977) 666-673. https://doi.org/10.1002/aic.690230507.

[37] C. Dumouchel, On the experimental investigation on primary atomization of liquid streams, Exp. Fluids. 45 (2008) 371-422. https://doi.org/10.1007/s00348-008-0526-0.

[38] Q.-F. Fu, L.-J. Yang, Y.-Y. Qu, B. Gu, Linear Stability Analysis of a Conical Liquid Sheet, J. Propuls. Power. 26 (2010) 955-968. https://doi.org/10.2514/1.48346.

[39] A. Turpin, A. Couvert, A. Laplanche, A. Paillier, Experimental study of mass transfer and H2S removal efficiency in a spray tower, Chem. Eng. Process. Process Intensif. 47 (2008) 886-892. https://doi.org/10.1016/j.cep.2007.02.002. 


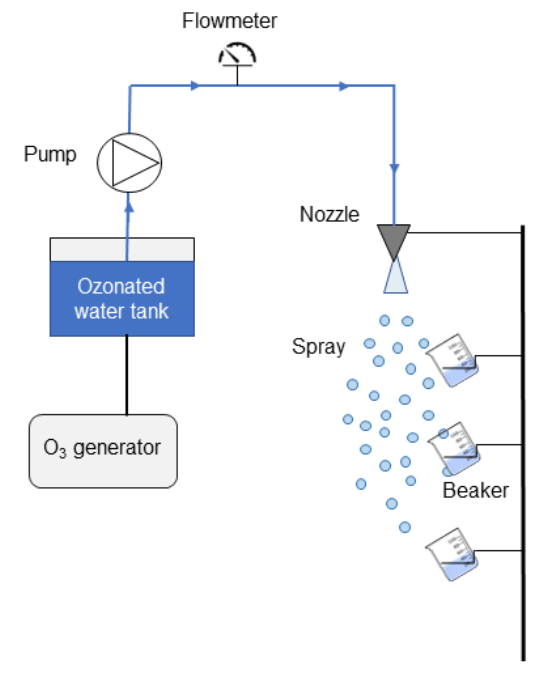

1

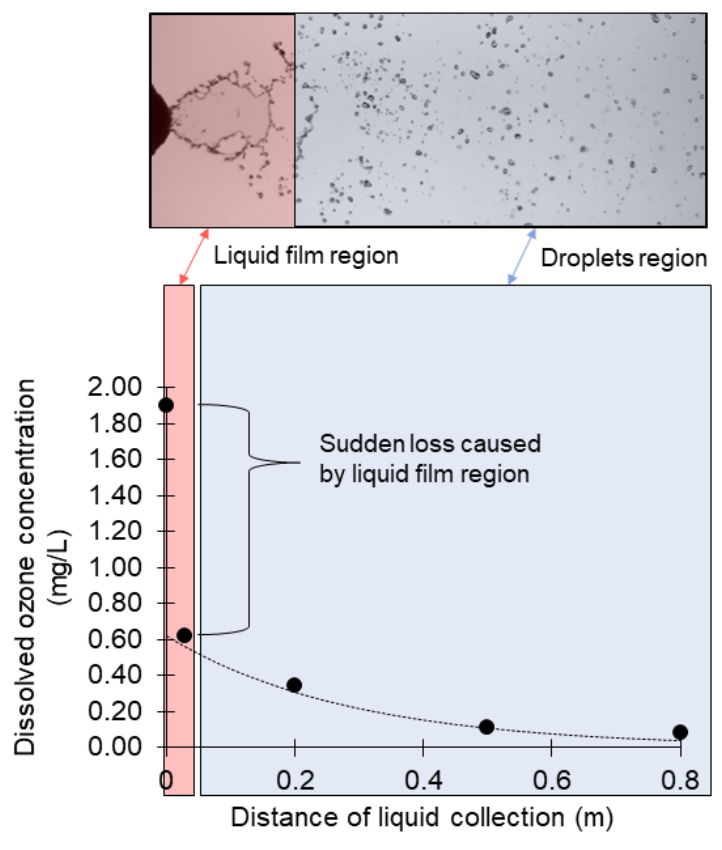

- Experiments
........ Model for droplets 